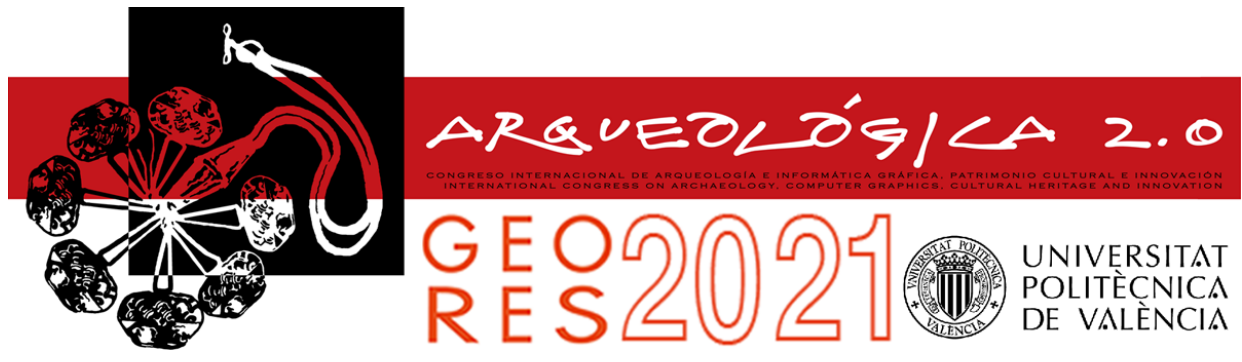

Proceedings of the joint international event $9^{\text {th }}$ ARQUEOLÓGICA

$2.0 \& 3^{\text {rd }}$ GEORES

Valencia (Spain).

26-28 April 2021

\title{
DEVELOPMENT OF AN INTEGRATED BIM-GIS MANAGEMENT TOOL FOR MAINTENANCE PLAN OF HISTORICAL HERITAGE
}

\author{
Ilaria Bonfantia, ${ }^{*}$, Elisabetta Coluccia, Valeria De Ruvo ${ }^{a}$, Matteo Del Giudice ${ }^{b}$, Sara Fasana ${ }^{b}$, \\ Emmanuele laconoc, Andrea Maria Lingua ${ }^{a}$, Francesca Matrone ${ }^{a}$, Gianvito Marino Ventura ${ }^{c}$, Marco \\ Zerbinatti ${ }^{b}$ \\ a Department of Environmental, Land and Infrastructure Engineering (DIATI), Politecnico di Torino, C.so Duca degli Abruzzi 24, 10129 \\ Torino, Italy. ilaria.bonfanti@polito.it; elisabetta.colucci@polito.it; valeria.deruvo@polito.it; andrea.lingua@polito.it; \\ francesca.matrone@polito.it

\footnotetext{
${ }^{\mathrm{b}}$ Department of Structurall, Building and Geotechnical Engineering (DISEG), Politecnico di Torino, C.so Duca degli Abruzzi 24, 10129

${ }^{\mathrm{c}}$ Department of Economics and Business Studies (DISEI), Università del Piemonte Orientale, Via Duomo 6, 13100 Vercelli, Italy. emmanuele.iacono@uniupo.it; gianvito.ventura@uniupo.it
} \\ Torino, Italy. matteo.delgiudice@polito.it; sara.fasana@polito.it; marco.zerbinatti@polito.it
}

\begin{abstract}
:
The planned maintenance of cultural heritage $(\mathrm{CH})$, in recent years, has been strongly supported by innovations in the digital field and, in particular, by digital models. In this framework, Main10ance, an INTERREG project, aims to implement a plan of maintenance and conservation of the historical cultural heritage. The case study is the system of the Sacri Monti of northern Italy and Switzerland, groups of chapels and other architectural artefacts. The design phases are divided into: survey of the historical architectural heritage present; data processing and realisation of three-dimensional models with the help of BIM software; integration of the same in the geographical context through GIS support; creation of a database (DB) which creates interoperability between the various domains and which collects information on the characteristics of the heritage for maintenance and conservation purposes; possibility to make the information associated with 3D models accessible through demonstrators that allow interrogation of the DB and the models themselves. The data have been entered (planned maintenance records, history of activities, etc.), convey them into the DB structured according to the INSPIRE Directive (2007/2/EC, Infrastructure for spatial information in Europe) and CityGML standard with its Level of Detail - LODs) for the GIS representation and IFC for the BIM. The Italian National Unification (UNI) norms have also been considered for the DB design.
\end{abstract}

Keywords: planned maintenance, built cultural and historical heritage, HBIM, cityGML LoD, spatial database, multiscale approach

\section{Introduction}

The growing use and development of increasingly efficient and accurate 3D surveying and modelling techniques in geomatics are leading to numerous applications in the cultural heritage $(\mathrm{CH})$ field, especially for architectural, built and urban heritage. In the presented project, the integrated 3D metric survey and objectoriented modelling are used to support an easier administration of the architectural assets.

In particular, the contribution outlines the main elements of the Main.10.ance project. This work in progress is part of an international research program created to improve and enhance the management tools of the existing maintenance plans for architectural complexes, nowadays experimentally used at the Sacro Monte di Varallo Sesia. Thanks to the proposed methodology, we aim at structuring a functional model useful for different territorial realities and adaptable not only for similar artefacts but also for all the widespread heritage of our Countries.

It is, therefore, necessary to systematise procedures and maintenance protocols that have already been tested, as well as information models and intervention management programs, considering the complexity of the context and the diversity of information.

The information to be integrated derives not only from metric surveys and the geometries of the threedimensional models but also from glossaries ad hoc created to allow the use of a common language; historical and diagnostic investigations; reports of construction techniques; archival and iconographic sources; previous maintenance activities, with their diachronic periodicity,

`Corresponding Author: Ilaria Bonfanti, ilaria.bonfanti@polito.it 
and so on. Not least, glossaries ad hoc created to allow the use of a common language. Therefore, adequately addressing semantic aspects' management is crucial for setting up a valuable and dynamic tool.

\subsection{The Main.10.ance project}

Main10ance is a three-year research project (Interreg Italy-Switzerland "MAIN.10.ANCE", 2019-2021) and has as objective the creation of a tool to support the planned maintenance of the Italian and Swiss Sacri Monti. One of the aims is to develop the complete database structure for scheduled maintenance, conduct campaigns of integrated metric surveys, thereby developing 3D models, and harmonise technical terminology with specific glossaries. The present paper will explain this process.

The search for adequate applications able to manage an elaborate maintenance plan of Cultural Heritage led to the choice of adopting the BIM methodology (and the Historical Building Information Modelling - HBIM accordingly) for the architectural scale, integrating it in a GIS structure capable of providing more adequate tools for territorial and multiscale analysis. These tools and methods have, in fact, great relevance in the interpretative phase and for the "physical" knowledge of the asset. However, they can also provide a decisive contribution to the completion of the mere geometric models, making them even semantic and informative, thus proper for 360 degree planning of the maintenance of the historic architectural heritage.

Therefore, the database is divided into different Levels of Detail (LoD) to allow the development of simple and "scalable" tools, agile and useful for maintenance. The database is interoperable as it is based on international standards and is suitable and queryable by different users, from specialised maintenance technicians to restorers and tourists. This database forms an everyday basis for the HBIM models and the GIS environment and is managed by open source software (PostgreSQL).

Information of the geographical and territorial context is combined with geometric, morphological, material and interventions data on the site's chapels.

The project focuses on the dialogue of the two BIM and GIS domains, creating a demonstrator able to unify the different types of information at different levels of detail.

\section{The case study}

The object of the project is the system of the Sacri Monti of northern Italy and Switzerland, groups of chapels and other architectural artefacts, such as statues, like frescoes, wall painting and terracotta sculptures, erected mainly between the $\mathrm{XVI}$ and $\mathrm{XVII}$ century.

These are architectural complexes of high value, inserted in mountain landscapes and environmental contexts and declared part of the UNESCO World Heritage List in 2003 (Piedmont and Lombardy). The system consists of 7 Piedmontese, 2 Lombard and 2 Swiss sites (Fig. 1) and experienced their most excellent development during the Catholic Reformation, after the Council of Trento (15451563).

They were conceived and organised to bring the populations who lived along the subalpine arc closer to the Catholic faith, especially those near those penetrated by the Protestant Reformation. Therefore, they became places where, through the creation of works of art and the depiction of the life of Christ or the Saints, also illiterate people could have a clear understanding of the Christian message. Precisely for this reason, it is possible to find statues, frescoes and iconographic elements inside each chapel, thus complicating the overall management and maintenance.

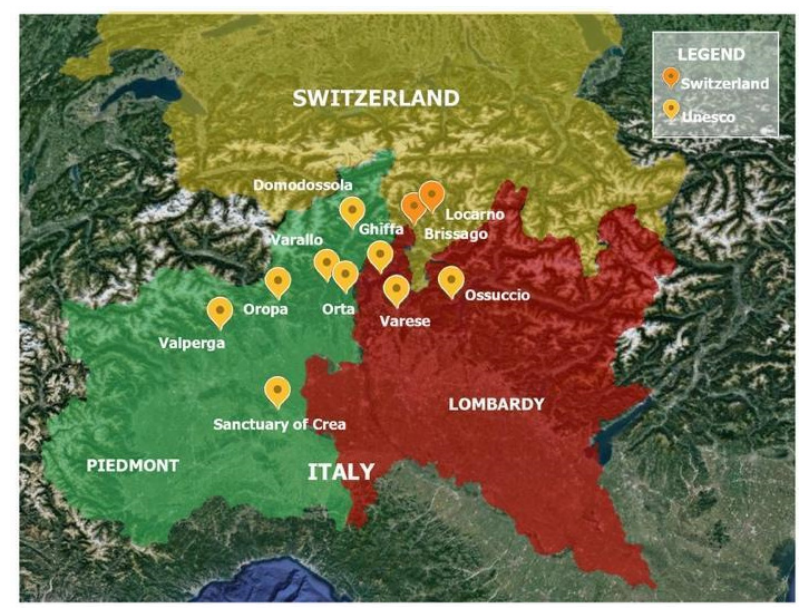

Figure 1: The system of "Sacri Monti" across Italy (Lombardy and Piedmont) and Switzerland.

\subsection{Survey Campaigns}

The survey campaigns for some complexes of the Sacri Monti have been conducted since 2015 and are still ongoing. In particular, to date, data of some buildings of the "Sacro Monte di Ghiffa" and a large part of the "Sacro Monte di Varallo" have been acquired with an integrated metric survey (Fig. 2).

The methods involved are:

- Integrated 3D metric survey. A planimetric network with static GPS/GNSS has been surveyed, with the integration of Real-Time Kinematic and topographic techniques. A Terrestrial Laser Scanner (FARO Focus) has been used for the data acquisition of indoor and outdoor parts. In contrast, a photogrammetric survey with UAVs (Unmanned Aerial Vehicles) has been conducted for the roofing.

- Rapid techniques. High cost (Stencil Kaarta) and low-cost sensors (smartphones, GoPro) have been tested (Calantropio, Matrone, \& Lingua, 2019).

For details on data acquisition and processing, refer to (Zerbinatti, Matrone, \& Lingua, 2020; Matrone, 2018; Lingua, Noardo, Spanò, Sanna, \& Matrone, 2017).

\section{Related Works}

Planned maintenance and the safeguarding of cultural and architectural heritage must take into account several factors. First, as mentioned above, the integration and management of different types of data and their easy handling by managers or users (Tommasi, Achille, Fanzini, \& Fassi, 2019). In this sense, the HBIM methodology offers an excellent support tool for the 
management of built heritage (Brumana, Georgopoulos, Oreni, Raimondi, \& Bregianni, 2013; GarcíaValldecabres, Pellicer, \& Jordan-Palomar, 2016; Brumana, Oreni, Raimondi, Georgopoulos, \& Bregianni, 2016; García, García-Valldecabres, \& Blasco, 2018; Bruno \& Roncella, 2019). Despite the still substantial limitations in the modelling of complex structures or decorative apparatuses, to which a solution can be found thanks to external modelling software and the use of NURBS (Oreni et al., 2014; Brumana et al., 2018; Diara \& Rinaudo, 2020), the ease of data management and its visualisation and the simplicity of updating, provides a reason why this methodology is increasingly used (Logothetis, Delinasiou, \& Stylianidis, 2015; Yang et al., 2020).

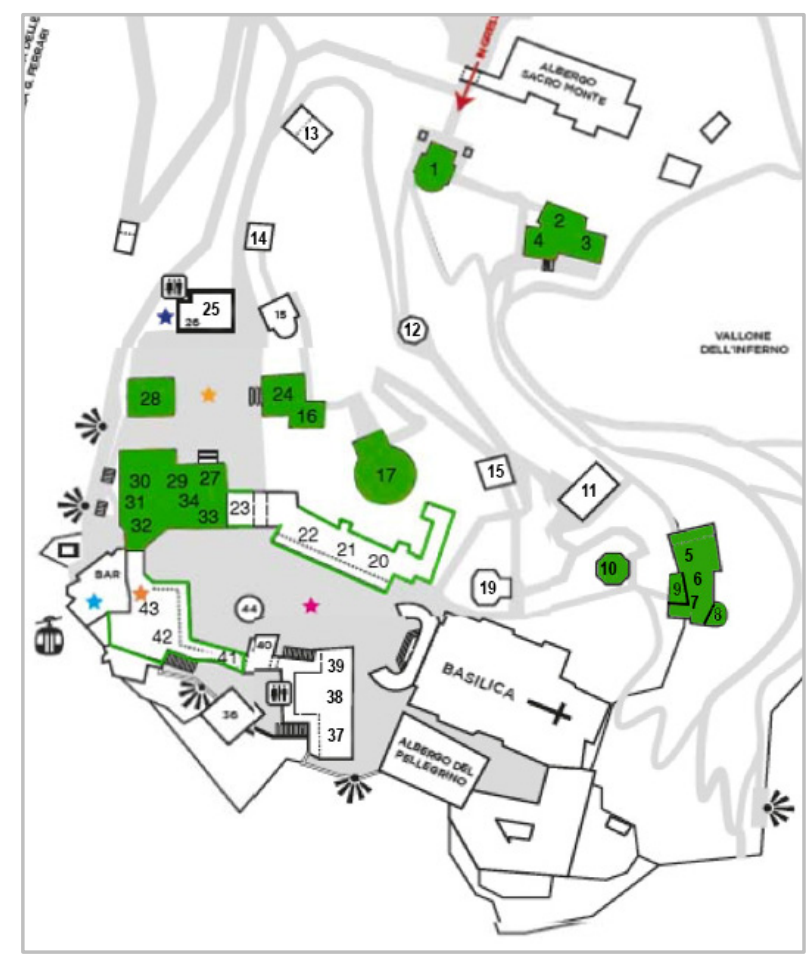

Figure 2: Plan of the Sacro Monte di Varallo. Starting from a complete photogrammetric survey of the whole complex integrated with laser scans, 21 chapels have been modelled with BIM methodology (green). For those with a green border the HBIM modelling is ongoing.

Furthermore, there is also an increasing interest in inserting HBIM models in their urban-environmental context, thus allowing more articulated, complex and complete analyses (Vacca, Quaquero, Pili, \& Brandolini, 2018; Matrone, Colucci, De Ruvo, Lingua, \& Spanò, 2019; Bruno et al., 2020; Colucci, De Ruvo, Lingua, Matrone, \& Rizzo, 2020; Tsilimantou, Delegou, Nikitakos, Ioannidis, \& Moropoulou, 2020). In some of these cases, however, there is no unique interoperable database capable of containing both data from the BIM and GIS domains. The management of these two domains usually occurs by importing the HBIM model into the GIS environment, not taking into account the full integration of the data structure and sources, instead verifying only the actual reading of the semantic component of the model. The methodology proposed here, instead, seeks to build a common database and create a demonstrator able to manage both the IFC (Industry Foundation Classes) structure and the data (geometries and attributes) coming from the GIS.
Furthermore, even within the same BIM domain, an additional element is added here compared to other research works. Since there are 11 sites with many chapels inside each one (only the Sacro Monte di Varallo has 45 chapels), it is not enough to manage a single HBIM model into the GIS environment. Still, it is necessary to create federated models for each site. There is, therefore, the definition of a LoD for the statues, decorations and so on, to then move to the architectural one of the individual chapels, then to the urban one of each complex, the regional one of the Italian Sacri Monti and finally the supra-national one with the integration of the Swiss Sacri Monti.

\section{Methodology}

This study aims to create a simple to use tool, scalable to different case studies, interoperable for other domains and easily accessible by multiple types of users. The interoperability of the database between the GIS domain and the BIM domain is made possible thanks to the use of international standards; this allows to extend the applicability of this methodology in contexts with similar characteristics (widespread historical architectural heritage). The realisation of integrated three-dimensional visualisation tools and management of a single database must allow different users to have access and be able to modify and manage information belonging to the different levels of detail of the Sacri Monti. The maintenance technician shall have access to all levels of detail for scheduled maintenance, and the simple tourist must have access to information relating to the topography of the place and then the spatial data for guidance and knowledge of the architectural and artistic works of the Sacri Monti.

\subsection{Tools and Interoperability}

The research highlights the need to enhance the interoperability between different domains, data models and software; for this reason, many national and international standards have been studied and considered. They allow geometric, semantic, and technical interoperability among different environments such as BIM, GIS, existing documentation, etc.

Among these, it is possible to identify: standards in the BIM domain (1), geographic representation data models (2) and standards for architectural and built heritage documentation (3).

Depending on the software used and, therefore, the types of information stored, different international standards have been taken into account:

- $\quad I F C$, Industrial Foundation Classes, is an open data format to facilitate interoperability between different operators. It allows the interchange of an information model without loss or distortion of data or information (https://technical.buildingsmart.org/standards/ifc ).

- UNI 11337-5:2017, for Construction and civil engineering works, Digital management of building information processes, Part 5, information flows in digitised processes. It defines the roles, rules and flows necessary for 
the production, management and transmission of information in the digitalised construction processes

(https://www.uni.com/index.php?option=com_c ontent\&view=article\&id=5753\%3Agestione-

digitale-dei-processi-informativi-delle-

costruzioni-pubblicate-le-parti-1-4-e-5-della-uni11337).

For as regard the GIS environment the standards adopted are:

- INSPIRE, Infrastructure for Spatial Information in Europe (https://inspire.ec.europa.eu/). It aims at the representation of homogeneous data to support environmental analysis in Europe.

- Open Geospatial Consortium (OGC) CityGML, (https://www.ogc.org/standards/citygml). It is an exchange format to store digital 3D models of cities and landscapes. It defines different standard levels of detail (LoDs) for the 3D objects, which allows the representation of objects for different applications and objectives.

- $\quad$ BDTRE, Base Territoriale di Riferimento degli Enti,

(https://www.geoportale.piemonte.it/cms/bdtre/b dtre-2). It is the Piedmont Region Geoportal, INSPIRE compliant (Technical Regional Map).

Then, for architectural and cultural heritage representation, it is possible to select:

- $\quad$ The Getty Vocabulary, specifically The Getty Art and Architecture Thesaurus (AAT), (https://www.getty.edu/research/tools/vocabular ies/aat/). It is a structured vocabulary, including terms, descriptions, and other metadata for generic concepts related to art, architecture, conservation, archaeology, and other cultural heritage. Included are work types, styles, materials, techniques, and others (https://www.getty.edu/research/tools/vocabular ies/).

- $\quad$ CIDOC-CRM, the Conceptual Reference Model is the core ontology for cultural heritage. It can help researchers, administrators and the public explore complex questions regarding our past across diverse and dispersed datasets (http://www.cidoc-crm.org/).

- UNI 11182:2006, Cultural heritage, Natural and artificial stone materials, Description of alteration form, Terms and definitions.

\subsection{The Glossary}

The "Illustrated Glossary" contains the terms used to describe the constituent materials, previous interventions and degradation phenomena related to stone materials and decorated surfaces of architecture (wall paintings, graphite, plaster). Based on the general terms (alteration, degradation and damage), we classify the phenomena of decay of materials, the executive technique (characteristics of each element and how it was realised) and previous interventions. From this information, it is possible to define the state of conservation of the material and the level of urgency of intervention that are important for the planning of the maintenance.

\subsection{The database design}

The design of Sacri Monti DB aims to start from a complex world, represented by perceived reality, reaching its implementation in a language comprehensible to the computer. It is a database organised according to different levels of detail, as defined by the CityGML standard, further deepened up to a Lod 5, regarding the aspects related to maintenance.

Firstly, the objects for which to store information in the data model were chosen. Therefore, it has been defined as the so-called "external model", made up of the entities with which to simplify the complex reality. These entities were selected from among the geographical data shared by the BDTRE standard; the INSPIRE standard has been chosen for raster data, the IFC one for BIM objects and a glossary drew up based on UNI 11182:2006 has been used. The next stage of DB design involves the definition of a "conceptual model", which represents a formal description of the "external model", based on well-defined and straightforward rules. It represents the model "entity relationships", in which the various entities are distinguished. The aim is to record information in the form of "attributes" for each entity. In this phase the relations between two entities have been defined, specifying the "cardinalities", which represent the minimum and the maximum number of possible occurrences.

The "conceptual model" (Fig. 3) has been subsequently schematised in the "logical" one, through which a structure of data has been expressed in a useful form to the computer. Precisely, it is a "relational model" based on the storage of data expressed in the form of numbers, strings and identifiers. At this stage, both the modalities with which to store the data and the modalities to connect two entities through a common field have been defined.

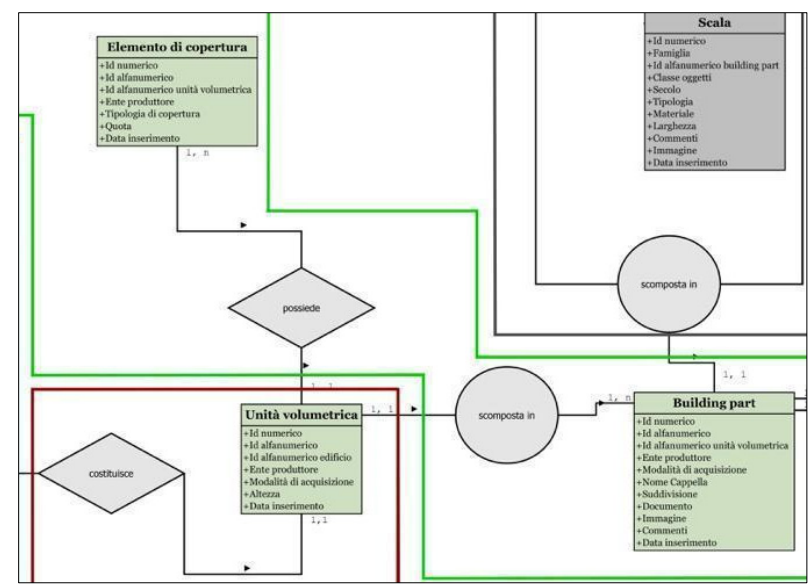

Figure 3: Excerpt of the Conceptual model with the links between "Roofing element", "Volumetric units", Building part, "Staircase").

The final design phase concerns the realisation of the "logical model" (Fig. 4) in the "internal" one, which represents the implementation of a database in a language comprehensible to the computer, so that the 
creation, manipulation and efficient query of data can be carried out.

The open-source object-relational database system PostgreSQL (https://www.postgresql.org/) was chosen for the implementation of the DB, for the possibility through the PostGIS extension to perform geospatial queries on the database and for its compatibility with all major operating systems. PgAdmin has been adopted as a graphical client for the DB Postgresql's simplified administration, allowing the creation of tables and their population. To enable the GIS connection, the PostGIS extension has been added.

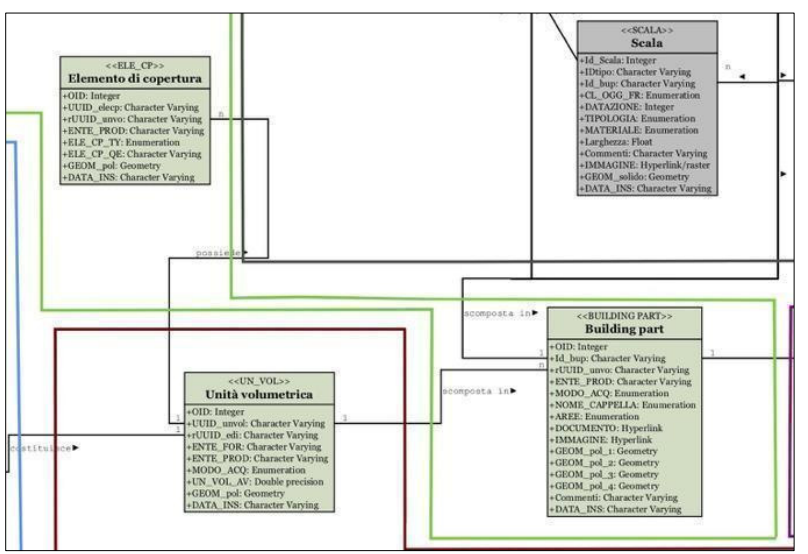

Figure 4: Excerpt of the Logical model with the links between "Roofing element", "Volumetric units", Building part, "Staircase").

Hence, this process's outcome is the creation of a GIS, in which the DB is connected, allowing its population with vector and raster data. For the geometries visualisation and querying the open-source software QGIS has been used (https://www.qgis.org/en/site/). Through PostgreSQL the relationships between the data have been created to make them questionable.

Each created table corresponds to the different entities represented in the logical model. It has been defined fields, data type, primary key, and any existing constraints for each one of them. In the case of $n: m$ relation type, it was necessary to create additional tables, all indicated with the prefix "nm", followed by the names of the two related tables. In the case of "enumeration" data, socalled "types" were also created and "labels" were defined for each of them. Everything has been embedded in a scheme, created explicitly for this project.

The subdivision in LOD makes different available levels of scale of information that correspond to different target users. The more general information about the geographical and topographical context in the LODO (digital soil model, roads, woods, watercourse areas, significant locations, etc.) is implemented by other more specific information about the building, to its volume, to the inner secondary roads to the Sacro Monte, in LOD1. The LOD2 contains three-dimensional information of the soil and the masses of the individual chapels of the Sacri Monti (covering elements, topography and soil surface model, building part, etc.). The first levels of detail are based on national and international standards, BDTRE (regional standard), INSPIRE (for raster data) and IFC (Industry Foundation Classes) only for the entity Building part, that is the mass of the individual chapels of Sacro
Monte. The geometric and data information of the individual structural and architectural elements (floor, roof, wall, staircase, etc.) is connected directly to the Building entity part of the chapels' individual masses. This is the LOD3 that represents the level of scale connected to the BIM domain and $3 \mathrm{D}$ modelling, and refers to the international IFC standard. Level of detail 4 collects the entities related to the decorative elements present inside the chapels (painting, mosaic, mural painting, etc.). The additional level of detail (LOD5), created ad-hoc for the present project, is characterised by alphanumeric information related to maintenance planning and programming. The characteristic entities (risk, control, damage, degradation, etc.) and those of LOD4, are subject to a hierarchical coding of an illustrated Glossary containing the terms used to describe the constituent materials, previous interventions and degradation phenomena related to stone materials and decorated surfaces of architecture.

\section{First Results}

This work aims to show the first project results developed in the first year of the research.

Thanks to the continued collaboration among all the partners, it was possible to achieve different valuable results.

Firstly, creating an interoperable spatial database structured following existing and international standards, then the DB population with geometries and attributes deriving from the Glossario and many suggestions of administrative and management parts of Sacri Monti.

Finally, the creation of the BIM models thanks to the 3D metric survey data.

All these outcomes will be helpful in the next steps of the project aimed at the BIM-GIS integration and the DB query and implementation with new parameters by technicians.

\subsection{Database population in PostgreSQL, DB connection in GIS and LODs visualisation}

After the creation of the internal model and its entities, the first LODs have been populated with attributes and geometries deriving from different standards above mentioned (such as Geoportals vector data and INSPIRE raster entities).

Georeferenced spatial data was returned via the open Quantum GIS software. Information on the territory, the mapping and topography of the area, the green, the urban furnishings, and all the geometric and alphanumeric information necessary for the maintenance plan's construction were added.

Firstly, the connection to the PostgreSQL database was created, configuring a series of parameters (e.g. database name, IP address, port on which the DB is exposed). Then, thanks to the "Data Source Manager" tool, all the layers corresponding to the tables built in the $\mathrm{DB}$, were added on map. These are still in lack of information, both geometric and semantic.

As regards the territorial scale data, corresponding to LoD0, LoD1 and LoD2, the shapefiles available on the Geoportal of Piedmont region and organised according to the BDTRE standard, have been used and their attribute 
tables have been copied into the appropriate ones created in the database Postgres.

By saving the QGIS project changes and refreshing the database connection, everything can be easily viewed on the PgAdmin client. This means that database tables now contain all the desired geometric and semantic information (Fig. 5).

\subsection{BIM tools}

HBIM methodology, an effective system to reconstruct intelligent 3D models of historic buildings, to manage information useful for cultural heritage interventions, was used to complete the higher levels of detail of the database. The modelling of the individual buildings making up the Sacri Monti was carried out through the use of the Autodesk Revit software, through a reverse engineering process with which all the architectural elements were created, integrated with all the information necessary for planned maintenance at this scale. These made it possible to create virtual representations associated with information previously determined in the database's logical structure.

The processing of a large number of three-dimensional data collected during the digital survey has generated a series of georeferenced point clouds, allowing to work on separate models with the ability to reassemble each Sacri Monti's models through subsequent federation, thanks to the possibilities offered by the options of connection between models within the software used. This will allow end-users to view the entire complex or a single chapel based on their tasks and, therefore, access the information.

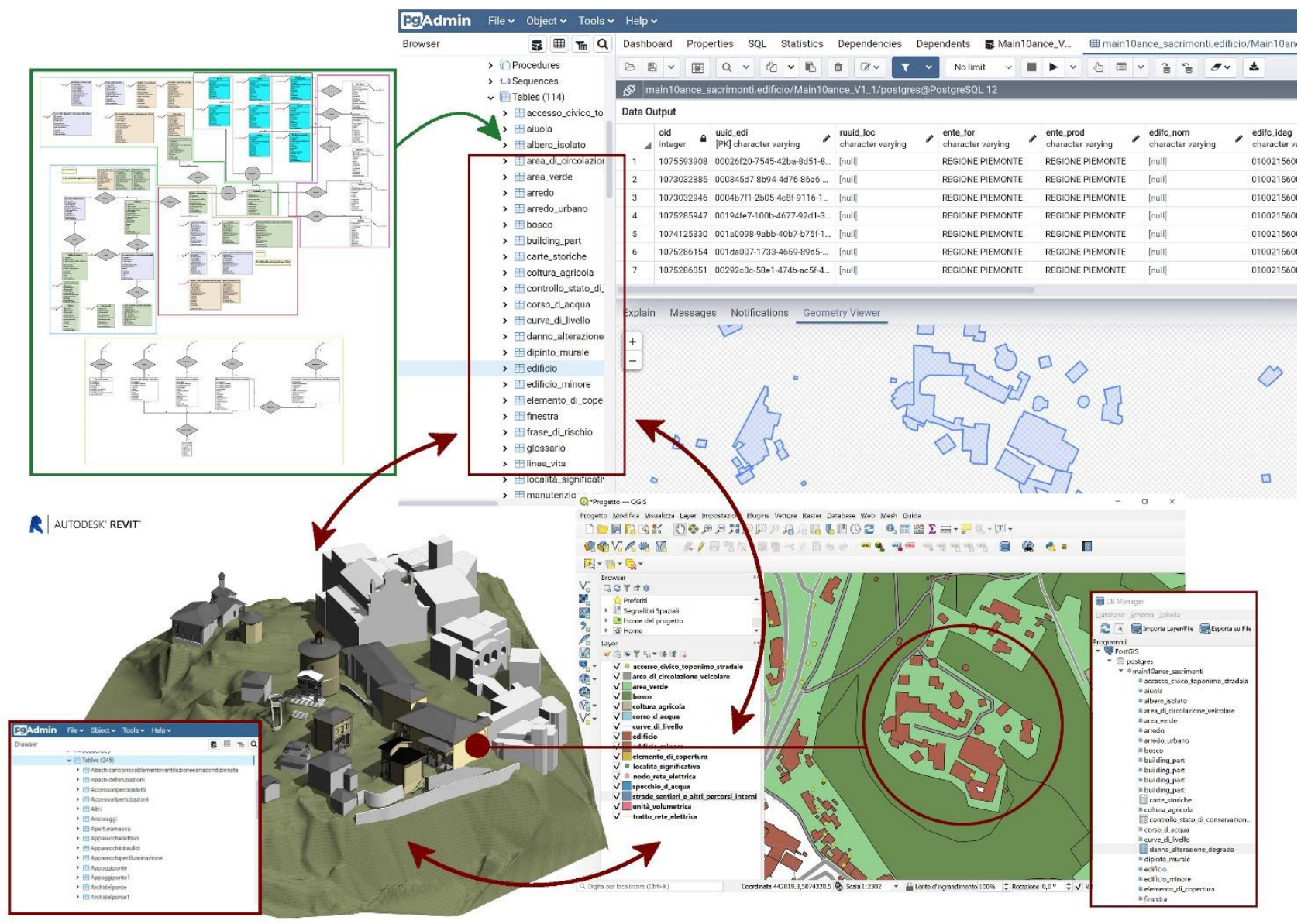

Figure 5: Connection between Main10ance DB with geometric and semantic data on PostgreSQL, QGIS DB and Revit-BIM DB (Sacro Monte of Varallo).

To model optimally and efficiently, the point clouds were divided into sections and subsections to facilitate operations and ease the software's computing load. In order to create the various elements making up the buildings of the Sacri Monti, a series of Revit families were created and subsequently parameterised, belonging to multiple categories (doors, windows, parapets, stairs, columns, etc.). This process of creating and parameterising families allows collecting, at the end of the modelling operations, a series of parametric objects which, gathered together, form a sort of database of historical BIM architectural elements, thus generating an additional project output that can be reused in future similar applications.

Finally, a script was created with Dynamo, a Visual Programming Language (VPL) tool, to test the possibility of creating a two-way information bridge between the modelling software and PostgreSQL. This made it possible to export not the entire BIM database as Revit DBLink would usually do, but to filter only the necessary geometric and alphanumeric information, populating the database attributes. These tests confirmed the possibility of achieving the final goal, the integration of GIS and BIM domains, combining data from different LODs from the 
territorial to the architectural scale, and also the bidirectionality of the data flow for a continuous updating of the models, all according to international standards (UNI 11337, ISO 19650).

\section{Discussions and Conclusions}

Built, historical and architectural heritage are values to be safeguarded and protected. For this reason, the design of a suitable tool that allows to manage and program maintenance activities is nowadays indispensable. Despite the known interoperability issues of BIM-GIS integration, this work aims to present a complete tool able to support maintenance plans of historical heritage. The database platform, developed with open source software, wants to be accessible and guarantee a user-friendly system to store, edit, and update $\mathrm{CH}$.

The interoperability of a database structure is essential for defining a complete instrument to operate at various scales of knowledge representation.
Finally, the ongoing research focuses on creating new controls, including a valuable dashboard for an immediate understanding of complex and multiscale data through graphs or charts and the option to modify only specific parameters according to the login type. This element lets the specialised user, authorised for the access, modify and record new data to be sent to the database.

\section{Acknowledgements}

For the present study, the authors would like to thank the director of management of the Sacri Monti and all the staff members for their support during all the project phases and the Department of the University of Italian Switzerland (SUPSI - Professional University School of Italian Switzerland) for the help and consultancy in the database design.

\section{References}

Brumana, R., Della Torre, S., Previtali, M., Barazzetti, L., Cantini, L., Oreni, D., \& Banfi, F. (2018). Generative HBIM modelling to embody complexity (LOD, LOG, LOA, LOI): surveying, preservation, site intervention-the Basilica di Collemaggio (L’Aquila). Applied geomatics, 10(4), 545-567.

Brumana, R., Georgopoulos, A., Oreni, D., Raimondi, A., \& Bregianni, A. (2013). HBIM for documentation, dissemination and management of built heritage. The case study of St. Maria in Scaria d'Intelvi. International journal of heritage in the digital era, 2(3), 433-451.

Brumana, R., Oreni, D., Raimondi, A., Georgopoulos, A., \& Bregianni, A. (2016). From survey to HBIM for documentation, dissemination and management of built heritage: The case study of St. Maria in Scaria d'Intelvi. In 2013 Digital Heritage International Congress (DigitalHeritage) (Vol. 1, pp. 497-504). IEEE.

Bruno, N., Rechichi, F., Achille, C., Zerbi, A., Roncella, R., \& Fassi, F.( 2020). Integration of historical GIS data in a HBIM system, Int. Arch. Photogramm. Remote Sens. Spatial Inf. Sci., XLIII-B4-2020, $427-434$. https://doi.org/10.5194/isprs-archives-XLIII-B4-2020-427-2020

Bruno, N., \& Roncella, R. (2019). HBIM for conservation: A new proposal for information modelling. Remote Sensing, 11(15), 1751

Calantropio A., Matrone, F., \& Lingua, A.(2019). Data integration of photogrammetric and laser-visual-inertial odometry based sensors in the metric survey of cultural heritage. Proceeding of R3 in GEOMATICS: Research, Results and Review, Naples 10-11 October.

Colucci, E., De Ruvo, V., Lingua, A., Matrone, F., \& Rizzo, G. (2020). HBIM-GIS integration: From IFC to cityGML standard for damaged cultural heritage in a multiscale 3D GIS. Applied Sciences, 10(4), 1356.

Diara, F., \& Rinaudo, F. (2020). Building Archaeology Documentation and Analysis Through Open Source Hbim Solutions via Nurbs Modelling. The International Archives of Photogrammetry, Remote Sensing and Spatial Information Sciences, 43, 1381-1388.

García, E. S., García-Valldecabres, J., \& Blasco, M. J. V. (2018). The use of HBIM models as a tool for dissemination and public use management of historical architecture: A review. Building Information Systems in the Construction Industry, 101.

García-Valldecabres, J., Pellicer, E., \& Jordan-Palomar, I. (2016). BIM scientific literature review for existing buildings and a theoretical method: proposal for heritage data management using HBIM. In Construction Research Congress 2016 (pp. 2228-2238).

Lingua, A., Noardo, F., Spanò, A., Sanna, S., \& Matrone, F. (2017).3D model generation using oblique images acquired by UAV. Int. Arch. Photogramm. Remote Sens. Spatial Inf. Sci., XLII-4/W2, 107-115. https://doi.org/10.5194/isprsarchives-XLII-4-W2-107-2017

Logothetis, S., Delinasiou, A., \& Stylianidis, E. (2015). Building information modelling for cultural heritage: a review. ISPRS Annals of the Photogrammetry, Remote Sensing and Spatial Information Sciences, 2(5), 177.

Matrone, F. (2018). Modelli HBIM da nuvola di punti: la verifica metrica dei dati e la valutazione dei risultati / Matrone, Francesca. - In: Bollettino della società italiana di fotogrammetria e topografia. - ISSN 1721-971X. - 2, pp. 1-9.

Matrone, F., Colucci, E., De Ruvo, V., Lingua, A., \& Spanò, A. (2019). HBIM in a semantic 3D GIS database. International 
Archives of the Photogrammetry, Remote Sensing \& Spatial Information Sciences.

Oreni, D., Brumana, R., Banfi, F., Bertola, L., Barazzetti, L., Cuca, B., \& Roncoroni, F. (2014). Beyond crude 3D models: from point clouds to historical building information modelling via NURBS. In Euro-Mediterranean Conference (pp. 166-175). Springer, Cham.

Tommasi, C., Achille, C., Fanzini, D., \& Fassi, F. (2020). Advanced Digital Technologies for the Conservation and Valorisation of the UNESCO Sacri Monti. In Digital Transformation of the Design, Construction and Management Processes of the Built Environment (pp. 379-389). Springer, Cham.

Tsilimantou, E., Delegou, E. T., Nikitakos, I. A., Ioannidis, C., \& Moropoulou, A. (2020). GIS and BIM as Integrated Digital Environments for Modelling and Monitoring of Historic Buildings. Applied Sciences, 10(3), 1078.

Vacca, G., Quaquero, E., Pili, D., \& Brandolini, M. (2018). GIS-HBIM INTEGRATION FOR THE MANAGEMENT OF HISTORICAL BUILDINGS. International Archives of the Photogrammetry, Remote Sensing \& Spatial Information Sciences, 42(2).

Yang, X., Grussenmeyer, P., Koehl, M., Macher, H., Murtiyoso, A., \& Landes, T. (2020). Review of built heritage modelling: Integration of HBIM and other information techniques. Journal of Cultural Heritage.

Zerbinatti, M., Matrone, F., \& Lingua, A. (2020). Planned maintenance for architectural heritage. experiences in progress from 3D survey to intervention programmes through HBIM. In: TEMA Technologies, Engineering, Materials, Architecture. 